\title{
Percutaneous coronary intervention of left anterior descending artery due to in-stent restenosis after positive dobutamine stress echocardiography
}

\section{Mihajlo Kovačić*, Marko Hranilović}

Čakovec County Hospital, Cakovec, Croatia

\section{RECEIVED:}

January 24, 2018

ACCEPTED:

February 10, 2018

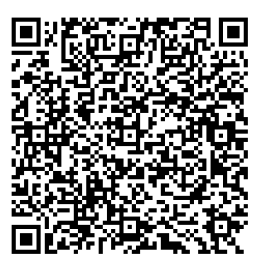

KEYWORDS: percutaneous coronary intervention, in-stent restenosis, stress echocardiography, strain and strain rate, transradial approach

CITATION: Cardiol Croat. 2018;13(1-2):41-42. | https://doi.org/10.15836/ccar2018.41

*ADDRESS FOR CORRESPONDENCE: Mihajlo Kovačić, Županijska bolnica Čakovec, I.G.Kovačića 1E, HR-40000 Čakovec, Croatia. / Phone: +385-98-266-774 / E-mail: mihajlo1983@gmail.com

ORCID: Mihajlo Kovačić, https://orcid.org/0000-0002-2577-9474 • Marko Hranilović, https://orcid.org/0000-0001-6522-5882

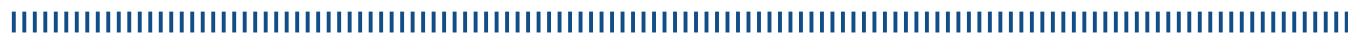

Introduction: Dobutamine stress echocardiography is based on the causal relationship between induced myocardial ischemia and left ventricular regional wall motion abnormalities. Strain and strain rate imaging have been applied to stress echocardiography as the most recent advancement striving to provide a more quantitative approach. ${ }^{1}$ The lumen diameter reduction after percutaneous coronary intervention (PCI) is known as "restenosis". In the era of bare metal stents (BMS) the occurrence of restenosis ranged between $17-41 \%$. Two strategies should be considered for treatment of any type of coronary in-stent restenosis (ISR): PCI with second or third generation drug eluting stents (DES) and drug coated balloons (DCB). ${ }^{2}$ We will present a case report of successful PCI for in stent restenosis of BMS of mid segment left anterior descending artery (LAD) with third generation DES after verification of ischemia with dobutamine stress echocardiography.

Case report: 75-years-old male patient with hypertension and dyslipidemia, who suffered anteroseptal ST-segment elevation myocardial infarction in January 2017, was treated with PCI of mid segment LAD with implantation of two BMS. One year after procedure he started to complain of mild exercise induced dyspnea. Standard treadmill ECG stress testing was performed up to a maximum predicted heart rate for his age and was without electrocardiographic evidence of cardiac ischemia. In further evaluation of symptoms, in January 2018 dobutamine stress echocardiography was performed, with maximal dose of $40 \mu \mathrm{g} / \mathrm{kg} / \mathrm{min}$. In rest setting, there was no visible regional akinesia of left ventricular wall, but in peak stress, test has clearly shown apicoseptal akinesia to dyskinesia. Both settings were quantitatively analyzed with strain and strain rate methods (Figure 1). After a positive stress echocardiography test, reevaluation with coronary catheterization was indicated due to suspected in stent

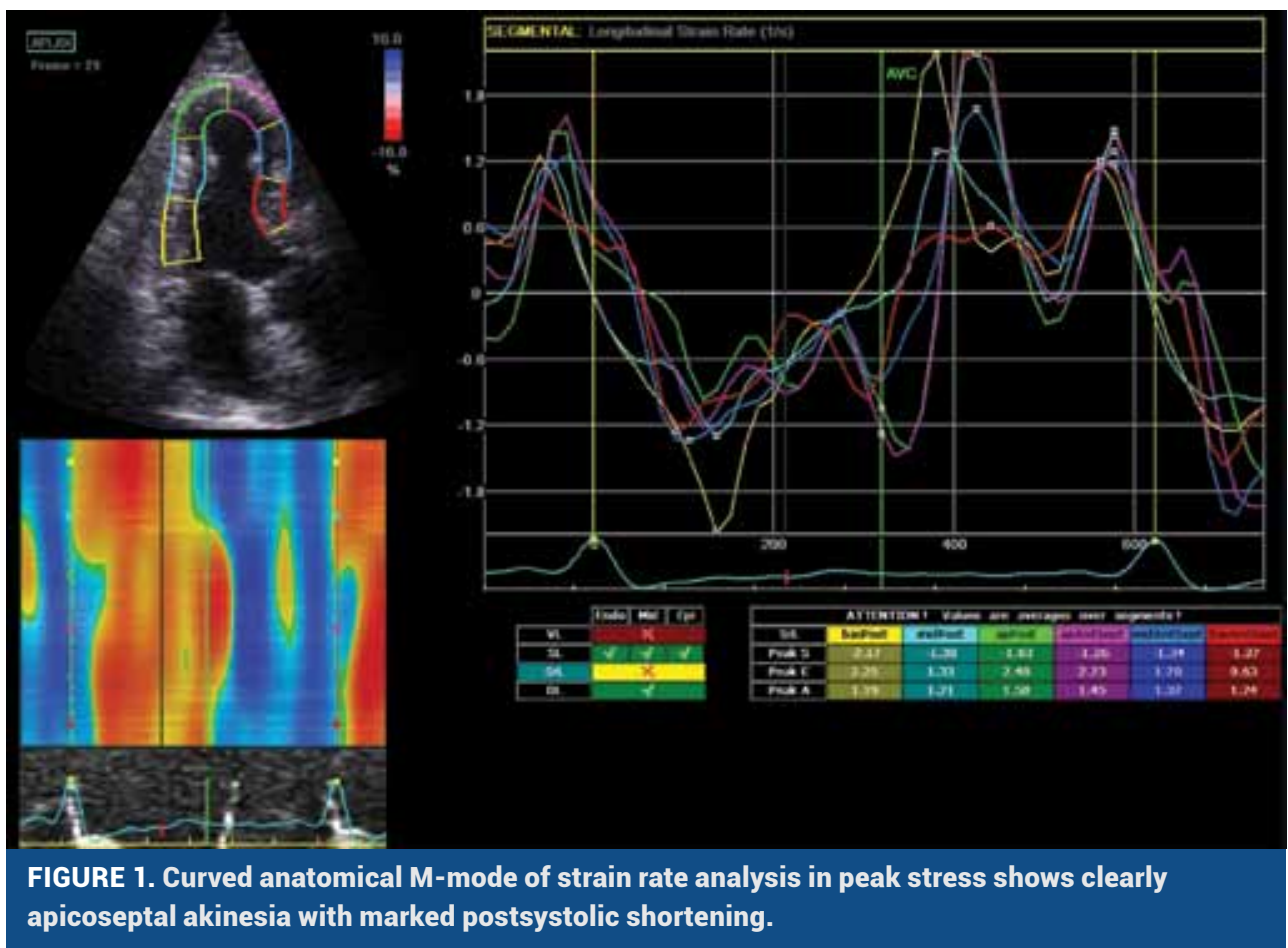


restenosis of BMS in mid segment of LAD. Cardiac catheterization was performed on $24^{\text {th }}$ of January 2018 and significant (90\%) ISR was determined (Figure 2). Using right transradial approach, vessel was cannulated with AL $1.06 \mathrm{~F}$ catheter due to anomalous left coronary artery. Lesion was predilated with NC balloon $2.75 \times 20 \mathrm{~mm}$, after which third generation DES 2.75x33mm was implanted (Ultimaster). Procedure was terminated after postdilatation with NC balloon 3.0x15mm, with finally TIMI 3 coronary flow (Figure 3).

Conclusion: In reevaluation of post myocardial infarction patients due to occlusive coronary disease in LAD region treated with PCI, stress ECG treadmill testing is not sufficient for analysis of left ventricular ischemia and possible target lesion failure detection. Stress imaging should be applied and stress echo with strain rate analysis can match sensitivity and specificity of single photon emission computed tomography or cardiovascular magnetic resonance imaging stress testing. PCI of ISR with second or third generation DES or DCB are methods of choice for treatment.
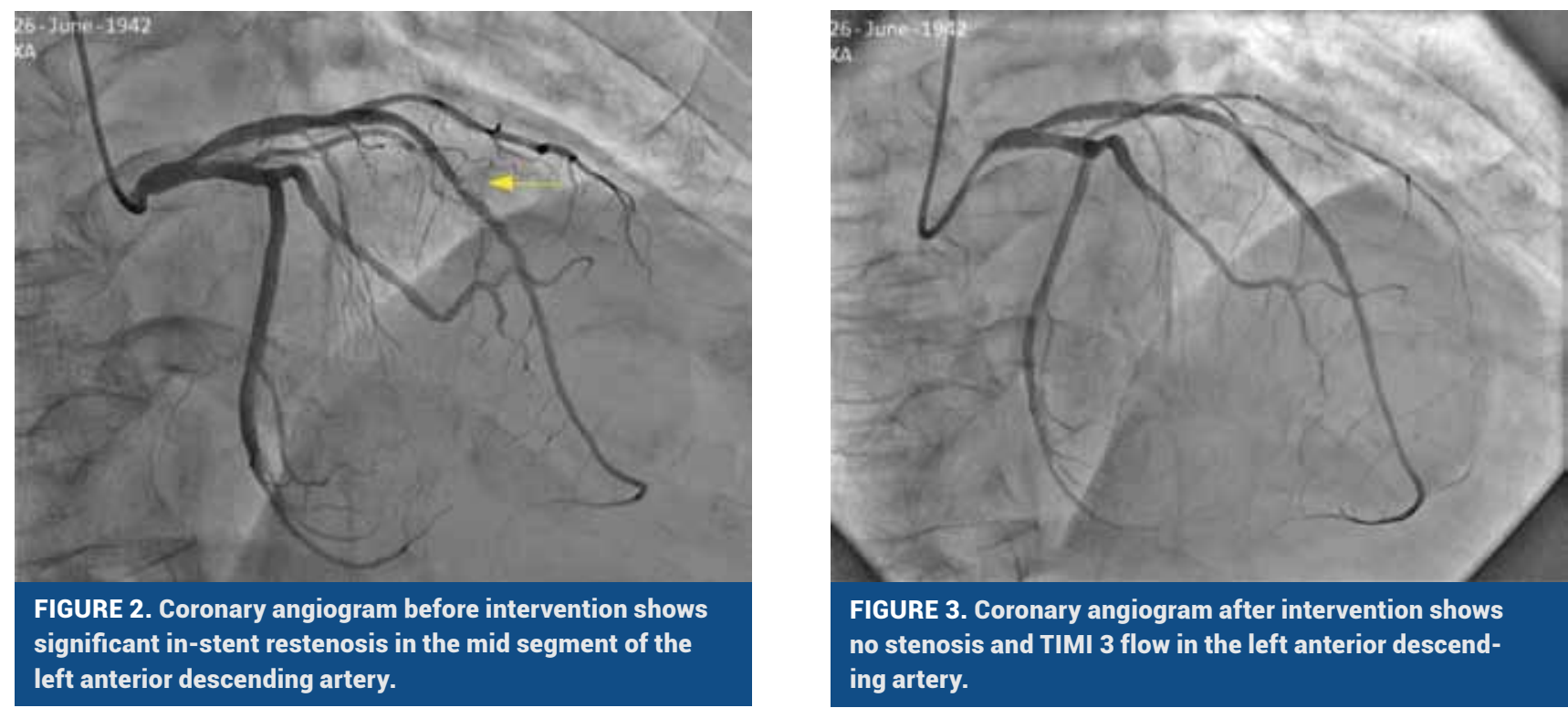

significant in-stent restenosis
left anterior descending artery.

\section{ing artery.}

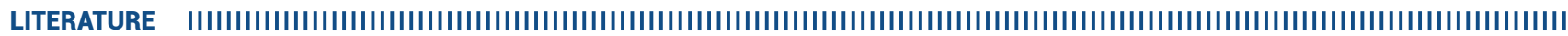

1. Armstrong WF, Ryan T. Feigenbaum's Echocardiography, 7th Edition, Lippincott Williams \& Wilkins, 2010.

2. Buccheri D, Piraino D, Andolina G, Cortese B. Understanding and managing in-stent restenosis: a review of clinical data, from pathogenesis to treatment. J Thorac Dis. 2016 Oct;8(10):E1150-E1162. https://doi.org/10.21037/jtd.2016.10.93 